\title{
Synthesis and in vitro characterizations of porous carboxymethyl cellulose-poly(ethylene oxide) hydrogel film
}

\author{
Su Yeon Lee ${ }^{1}$, Sumi Bang ${ }^{2}$, Sumi Kim, Seong Yeon Jo ${ }^{1}$, Bum-Chul Kim ${ }^{1}$, Yunjae Hwang ${ }^{1}$ and Insup Noh ${ }^{1,2^{*}}$
}

\begin{abstract}
Background: Cellulose and its derivatives such as carboxymethyl cellulose (CMC) have been employed as a biomaterial for their diverse applications such as tissue engineering, drug delivery and other medical materials. Porosity of the scaffolds has advantages in their applications to tissue engineering such as more cell adhesion and migration leading to better tissue regeneration. After synthesis of CMC-poly(ethylene oxide) (PEO) hydrogel by mixing the solutions of both CMC-acrylate and PEO-hexa-thiols, fabrication and evaluation of a CMC-PEO gel and its film in porous form have been made for its possible applications to tissue regeneration. Physicochemical and biological properties of both CMC-PEO hydrogel and porous films have been evaluated by using physicochemical assays by SEM, FTIR and swelling behaviors as well as in vitro assays of MTT, Neutral red, BrdU, gel covering and tissue ingrowth into the pores of the CMC-PEO gel films. Degradation of CMC-PEO hydrogel was also evaluated by treating with esterase over time.

Results: Chemical grafting of acrylate to CMC was verified by analyses of both FTIR and NMR. CMC-PEO hydrogel was obtained by mixing two precursor polymer solutions of CMC-acrylate and PEO-hexa-thiols and by transforming into a porous CMC-PEO gel film by gas forming of ammonium bicarbonate particles. The fabricated hydrogel has swollen in buffer to more than 6 times and degraded by esterase. The results of in vitro assays of live and dead, MTT, BrdU, Neutral red and gel covering on the cells showed excellent cell compatibility of CMC-PEO hydrogel and porous gel films. Furthermore the porous films showed excellent in vitro adhesion and migration of cells into their pore channels as observed by H\&E and MT stains.
\end{abstract}

Conclusions: Both CMC-PEO hydrogel and porous gel films showed excellent biocompatibility and were expected to be a good candidate scaffold for tissue engineering.

Keywords: Carboxymethyl cellulose, Poly(ethylene oxide), Gel film, Biocompatibility, Pores

\section{Background}

Cellulose polymer is the most abundant natural polysaccharide with glucose-based repeat units connected by 1,4-beta-glucosidic linkages. Its derivatives have been widely employed as polymeric materials in diverse industries including medical applications. As examples, carboxymethyl cellulose (CMC) [1], cellulose nitrate [2],

\footnotetext{
* Correspondence: insup@seoultech.ac.kr

'Department of Chemical and Biomolecular Engineering, Seoul National University of Science and Technology, 232 Gongneung-ro, Nowon-gu, Seoul 139-743, Republic of South Korea

${ }^{2}$ Convergence Institute of Biomedical Engineering and Biomaterials, Seoul National University of Science and Technology, 232 Gongneung-ro, Nowon-gu, Seoul 139-743, Republic of South Korea
}

cellulose acetate $[3,4]$ have been either fabricated into a hydrogel or drawn into fibers for textile applications and composite materials for safety glass. Unlike other natural polymers, cellulose derivatives have low water solubility due to formation of hydrogen bonding between hydroxyl groups in its side chains, leading to holding of the cellulose backbone chains together [5-8].

Biomedical applications of cellulose have included membranes for hemodialysis and diffusion-control and carriers for enzyme immobilization in biosensors, coating materials for drugs and scaffolds for drug-release and in vitro hollow fibers for perfusion [9-13]. Specially, CMC has been recognized as promising biomaterials due to their chemical properties for possibility of further 
modifications for tissue engineering of cartilage, disk and skin among others [14-16]. The obtained scaffolds showed advantageous properties such as mechanical strength and resistance to breakdown in vivo as well as biocompatibility and reactive surfaces for protein binding by controlling surface chemistry as well as biocompatibility for both granulation tissue and bone formation [17]. In other reports, the cellulose scaffold showed promotion of cardiac cell growth and enhancement of cell connectivity and electrical functionality [18]. Its densely packed chain structure also showed sufficient mechanical strength to support cell aggregations [18]. However, CMC has demonstrated limited in vivo biodegradation by hydrolysis, but slow releasing glucose as its final product at the same time [19-22].

In its applications to scaffolds for tissue regeneration, feasibility of diverse fabrications such as films, porous scaffolds and hydrogel with other medical polymers were considered as required important properties. Poly(ethylene oxide) (PEO), collagen, chondroitin sulfate and chitosan among many potential medical polymers have tried to be combined with cellulose for these purposes [23-25]. The scaffolds for tissue engineering have been fabricated in porous forms or films according to its application purposes [26]. Several studies recently reported possibility of its applications to bone and cartilage tissue engineering [27], hepatocyte culturing for an artificial liver [28-30], in vitro expansion of progenitor hematopoietic cells [31] and suppression of matrix metalloproteases action in wound healing $[12,32]$. Importantly, in vitro and in vivo evaluations of those cellulose-based materials have demonstrated excellent biocompatibility such as negligible foreign body and inflammatory response reactions [13,27-29]. Furthermore, porous CMC scaffolds demonstrated advantageous properties in tissue engineering such as formation of pathways for induction of better cell migration, better delivery of nutrients and bioactive molecules to growing cells and better removal of their wastes, thus providing better environment for tissue regeneration [31].

In this study, we fabricated in situ CMC-PEO hydrogel, and then transformed it into a porous gel film. Evaluation of both CMC-PEO hydrogel and a porous gel film showed both excellent physicochemical properties and in vitro biocompatibility. The results of in vitro tests furthermore showed both migration of the seeded cells and regeneration of extracellular matrix along the pores of the porous CMC-PEO gel scaffold, indicating possibility of its applications as a scaffold in tissue engineering.

\section{Method}

Materials

Poly(ethylene oxide) (PEO) polymer with hexa-thiols $(\mathrm{MW}=10 \mathrm{kDa})$ was purchased from Sunbio Inc. (Seoul,
Korea). While the chemicals of carboxymethyl cellulose sodium salt $(\mathrm{CMC})(\mathrm{MW}=90 \mathrm{kDa})$, adipic dihydrazide $(\mathrm{ADH})(\mathrm{MW}=174 \mathrm{kDa})$, acrylic acid $(\mathrm{MW}=72 \mathrm{Da})$, adipic acid dihydrazide (ADH), dimethyl sulfoxide (DMSO) and esterase solution from porcine liver (177 unit/mg) were purchased from Sigma-Aldrich Chemical Co. (MO, USA), N-(3-diethylpropyl)-N-ethylcarbodiimide hydrochloride (EDC) and 1-hydroxybenzotriazole hydrate (HOBt) were obtained from Fluka Chemie $\mathrm{GmbH}$ (Buchs, Switzerland). While DMEM-604 and penicillinstreptomycin were purchased from Lonza Korea (Switzerland), cell counting kit-8 (CCK-8) solution and live \& dead viability/cytotoxicity kit for mammalian cells were bought from Dojindo Laboratories (Japan) and Invitrogen (USA), respectively. Fetal bovine serum (FBS) and in vitro toxicology assay kits such as bromodeoxyuridine (BrdU), 3-(4,5-dimethylthiazol-2-yl)2,5-diphenyltetrazolium bromide (MTT) and Neutral red were purchased from Sigma-Aldrich (MO, USA), Roche (Germany) and Gibco BRL (Australia), respectively. All chemicals were employed as received.

\section{Synthesis of CMC-acrylate}

$\mathrm{CMC}$-acrylate was synthesized by sequential grafting of $\mathrm{ADH}$ and acrylic acid to $\mathrm{CMC}$ as below. $0.08 \mathrm{~g}$ ADH, $0.08 \mathrm{~g}$ HOBT and $0.10 \mathrm{~mL}$ EDC were separately added into $40 \mathrm{~mL} 5 \% \mathrm{CMC}$ solution, and then chemical reaction proceeded for $1 \mathrm{hr}$ (see overall schematics in Figure 1). After precipitating the resulting solution in ethanol, the products were dialyzed in distilled water with $50 \mathrm{~g} \mathrm{NaCl}$ by employing cellulose dialysis membrane filter with molecular weight cut off of $6 \sim 8 \mathrm{kDa}$. CMC powder was obtained by lyophilizing for $2 \mathrm{~d}$.

\section{Fabrications of CMC-PEO hydrogel and porous gel film}

The precursor solutions of both CMC-acrylates and PEOthiols were in advance sterilized separately with a $3 \mathrm{~mL}$ syringe by filtering them by a syringe filter with poly(ether sulfone) membrane (Pall Corp., PN4612; USA). The CMCPEO hydrogel was synthesized by mixing the sterilized precursor solutions in a 24 well plate overnight. Synthesis methods related have been reported in detail in our previous works $[8,31]$.

Porous CMC-PEO gel films were fabricated by adding ammonium bicarbonate porogens into the precursor solutions of CMC-acrylate and PEO-thiols. The pore sizes of hydrogel films were controlled by employing different concentrations of porogens (12 and 18\%) with different particle sizes ranging from $150-180$ to $250-350 \mu \mathrm{m}$. The porous gel films were obtained by gas forming the porogen particles. 


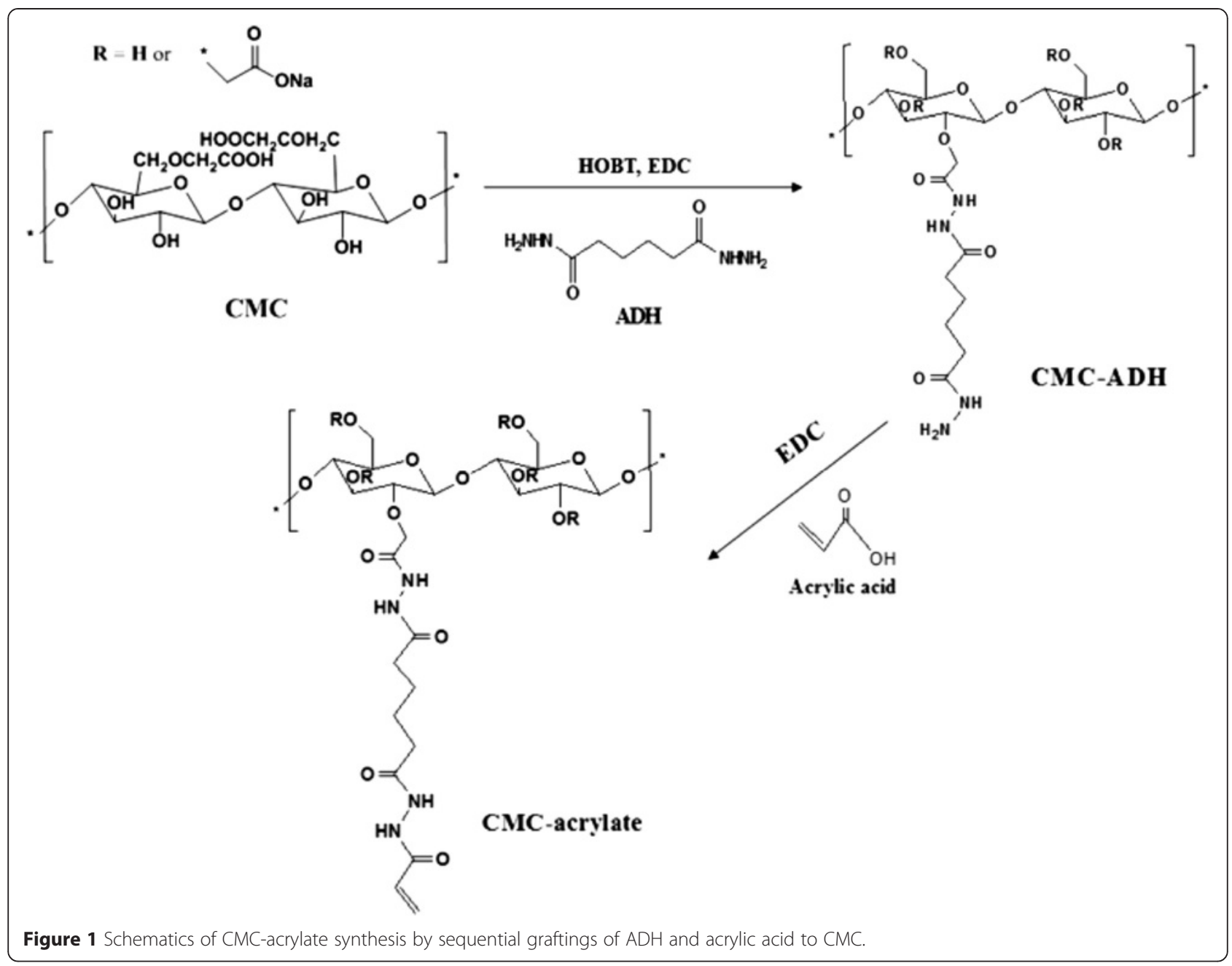

Attenuated total reflectance - Fourier transform infrared spectroscopy (ATR-FTIR)

After mixing $300 \mathrm{mg} \mathrm{KBr}$ and $1.0 \mathrm{mg} \mathrm{CMC}$ powders either with or without acrylated, a thin gel film (1.2 $\mathrm{cm}$ diameter and $1.0 \mathrm{~mm}$ thickness) was prepared by pressurizing $50 \mathrm{MPa}$ into a sample holder containing the mixed powder under vacuum for $3 \mathrm{~min}$. The gel film was chemically analyzed with an ATR-FTIR spectroscopy (FT/IR-62, Jasco; Japan). After establishing a standard curve with a polystyrene film, transmittance through the samples was scanned, ranging from 650 to $4000 \mathrm{~cm}^{-1}$.

\footnotetext{
${ }^{1} \mathrm{H}$ nuclear magnetic resonance ( $\left.{ }^{1} \mathrm{H}-\mathrm{NMR}\right)$

${ }^{1} \mathrm{H}$-NMR spectra were obtained by employing an UI $500 \mathrm{MHz}$ FT-NMR spectrometer (Varian, Japan) to observe an extent of grafting of acrylic acid to CMC. Chemical shift of the spectrum peak was measured for the samples of $\mathrm{CMC}$ and $\mathrm{CMC}$-acrylate, by using $1 \%$ deuterium oxide $\left(\mathrm{D}_{2} \mathrm{O}\right)(\mathrm{w} / \mathrm{v})$ as a solvent.
}

\section{Morphologies of dehydrated CMC-PEO hydrogel}

The morphologies of CMC-PEO gel films were visualized by a scanning electron microscopy (SEM; JEOL Ltd, Japan) after routine processing of dehydration and goldsputter coating of the gel films as below. The swollen gel films $(0.5 \times 0.5 \mathrm{~mm})$ were frozen in liquid nitrogen and then freeze-dried at $-55^{\circ} \mathrm{C}$ overnight (FD-8508, Ilshin Bio Base; Korea). The dry samples were mounted on an aluminum stub with a double-sided tape, and then gold-coated for $1 \mathrm{~min}$. The morphology of the dehydrated gold-coated CMC-PEO gel films was analyzed with SEM.

\section{Swelling of CMC-PEO hydrogel}

After measuring the gel weight with a microbalance, swelling of the 5\% CMC-PEO hydrogel was measured by immersing it in distilled water over time. Swelling behaviors of the CMC-PEO gel was also measured by immersing it in distilled water with different pHs at 4, 7 and 10. Adherent water was removed by blotting the wet CMCPEO gel with a piece of Kimwipe paper before weighing 
on an electronic balance. The percentage of the gel swelling was calculated by a following formula over its soaking time in distilled water at room temperature.

$$
\text { Swelling of the hydrogel }(\%)=\frac{(\mathrm{Ws}-\mathrm{Wi})}{\mathrm{Wi}} \times 100(\%)
$$

Where $W_{s}$ and $W_{i}$ are the swollen weight of the CMCPEO gel at time $t$ and its weight after gelation, respectively.

\section{Degradation of CMC-PEO hydrogel by esterase}

Degradation of 5\% CMC-PEO gel (1:1) was tried as below by addition of $2 \mathrm{~mL}$ esterase solution from porcine liver in distilled water. After swelling $200 \mu \mathrm{L}$ hydrogel in $2 \mathrm{~mL} \mathrm{DW}$, fresh esterase solution with either 2, 10 or 30 units was sprayed over the hydrogel at every $2 \mathrm{~d}$ $(n=3)$. The weight percentage of the remained hydrogel was calculated by employing flowing equation.

Gel weight loss by esterase $(\%)=\left(1-W_{\boldsymbol{e}} / \boldsymbol{W}_{\boldsymbol{c}}\right) \times 100(\%)$

$W_{e}$-weight of CMC-PEO gel treated with esterase at time $t$,

$W_{c}$-weight of CMC-PEO gel in water without esterase at time $t$.

\section{Evaluation of biocompatibility \\ In vitro cell behaviors on/in CMC-PEO hydrogel film}

Porcine aorta smooth muscle cells (passage 8) were in vitro cultured in DMEM-640 media (Lonza, Switzerland) containing both $10 \%$ fetal bovine serum (Lonza, Switzerland) and penicillin-streptomycin $(100 \mathrm{IU} / \mathrm{mL})$ (Lonza, Switzerland) in an in vitro incubator with $5 \%$ $\mathrm{CO}_{2}$ at $37^{\circ} \mathrm{C}$. Cell culture was performed by initial seeding of smooth muscle cells either inside or on the surface of $200 \mu \mathrm{L}$ CMC-PEO gel correspondingly at the densities of either 100,000 or 10,000 cells/ea for $7 \mathrm{~d}$. Cell culture plate with 24 wells was employed for loading of hydrogels. In vitro tissue regeneration was performed on the porous gel films by seeding 200,000 cells/scaffolds for $35 \mathrm{~d}$.

Cell adhesion and proliferation were evaluated with the assays of both cell counting kit-8 (CCK-8, Dojindo, Japan) and live \& dead after seeding smooth muscle cells at a density of 10,000 cells per sample. The cell number was counted as below with the CCK- 8 assay by using a microplate reader (Tecan, Australia), where the cell culture medium was measured as a background with the OD value of 1.2 to $1.4 .100 \mu \mathrm{L}$ CCK- 8 solution was inserted into the $900 \mu \mathrm{L}$ DMEM-640 medium and then the cell culture plate with samples was inserted in the in vitro $\mathrm{CO}_{2}$ incubator. After $2 \mathrm{hr}, 100 \mu \mathrm{L}$ medium with CCK-8 solution was aliquoted into a 96 well plate and an optical density of the CCK- 8 loaded medium was measured at the wavelength of $450 \mathrm{~nm}$ by the microplate reader.
In vitro cell viability was also observed with smooth muscle cells both inside and on the surface of the $200 \mu \mathrm{L}$ 5\% CMC-PEO gel. Live \& dead viability/cytotoxicity kit for mammalian cells was prepared according to the protocol suggested by the vendor (Invitrogen, USA) by adding the solutions of both $1.2 \mu \mathrm{L}$ ethidium homodimer-1 (EthD-1) (2 mM) and $4 \mathrm{mM}$ calcein AM $(0.3 \mu \mathrm{L})$ into $600 \mu \mathrm{L}$ PBS. After performing the reaction with the prepared agents for $30 \mathrm{~min}$ in the in vitro $\mathrm{CO}_{2}$ incubator, cell viability on the hydrogel was observed by a fluorescence microscope (Leica DMLB, Germany).

\section{In vitro direct contact of CMC-PEO gel with cells on tissue culture plate}

Effects of direct contact of the 5\% CMC-PEO gel on smooth muscle cells have been evaluated by covering the hydrogels on the cells in a 12 well plate. For the assay, smooth muscle cells were initially seeded at a density of $2 \times 10^{4}$ cell/well on a 12 well plate and then its surface was completely covered with either $200 \mu \mathrm{L}$ hydrogel, Teflon or Latex $(1 \times 1 \mathrm{~cm})$. After locating the samples carefully on the cells for $24 \mathrm{hr}$, both the cell growth characteristics and any signs of morphological change by cytotoxicity were observed by an inverted light microscope.

\section{Bromodeoxyuridine (BrdU) assay}

After loading 3 kinds of extract solution $(1 \mathrm{~mL})$ of the 5\% CMC-PEO gel, Latex and Teflon $\left(1 \times 1 \mathrm{~cm}^{2}\right)$, smooth muscle cells at a density of $1 \times 10^{4}$ cells were in vitro cultured in a 96 well plate for $24 \mathrm{hr}$. Cell culture lasted for another $2 \mathrm{hr}$ with addition of $10 \mu \mathrm{L}$ BrdU labeling solution. Subsequent to removal of labeling medium, solutions of both $200 \mu \mathrm{L}$ FixDenat and $100 \mu \mathrm{L}$ anti-BrdU peroxidase-labeled anti-BrdU antibody per well were treated, as suggested by the manufacturer. $25 \mu \mathrm{L} 1 \mathrm{M} \mathrm{H}_{2} \mathrm{SO}_{4}$ solution was added into each well after washing. Optical density of the samples was measured at an absorbance wavelength of $450 \mathrm{~nm}$ by the microplate reader by referencing that of $690 \mathrm{~nm}$.

\section{Thiazolyl blue tetrazolium bromide (MTT) assay}

After seeding smooth muscle cells in a 96 well plate at a density of $1 \times 10^{4}$ cells, cell culture lasted in a $5 \% \mathrm{CO}_{2}$ incubator at $37^{\circ} \mathrm{C}$ for $24 \mathrm{hr}$, and then $1 \mathrm{~mL}$ extracts of the 5\% CMC-PEO gel, Teflon and Latex $(1 \times 1 \mathrm{~cm})$ were added into the cell culture media for another $24 \mathrm{hr}$. Cell culture lasted for additional $4 \mathrm{hr}$ after insertion of $20 \mu \mathrm{L}$ MTT solution $(2 \mathrm{mg} / \mathrm{ml}$ in PBS) in the culture medium, and then sequential removal of the culture medium and addition of $100 \mu \mathrm{L}$ dimethyl sulfoxide followed. The optical density of the final solution was measured by the microplate reader at a wavelength of $570 \mathrm{~nm}$. 


\section{Neutral red assay}

Extracts from the 5\% CMC-PEO gel was obtained after loading the gel in the cell culture medium $(1 \mathrm{~mL})$ for $72 \mathrm{hr}$. Cell culture lasted in $5 \% \mathrm{CO}_{2}$ incubator at $37^{\circ} \mathrm{C}$ for $24 \mathrm{hr}$ after seeding smooth muscle cells on the hydrogel at a density of $1 \times 10^{4}$ cells/well. The medium was removed from the well, and then cell culture lasted for another $24 \mathrm{hr}$ after addition of the extract solution. Subsequent to addition of the culture medium and $0.33 \%$ Neutral red solution at a ratio of 9:1 in the in vitro incubator, cell culture lasted for another $2 \mathrm{hr}$. After washing with the fixation solution of the assay and then proceeding of reaction for $10 \mathrm{~min}, 100 \mu \mathrm{L}$ solubilization solution was added per well. Optical density was measured at an absorbance wavelength of $550 \mathrm{~nm}$ by the microplate reader by referencing that of $690 \mathrm{~nm}$.

\section{Histological staining of the in vitro tissue-regenerated porous CMC-PEO gel film}

The porous CMC-PEO gel films in vitro cell cultured were visualized by light microscopy after staining with hematoxylin and eosin (H\&E) and Masson's trichrome (MT) as below. H\&E stain was processed after crosslinking the cell-cultured porous CMC-PEO gel films with $4 \%$ paraformaldehyde for $1 \mathrm{~d}$ and then stored in a refrigerator in phosphate buffered solution. After paraffin embedding of the samples (Tissue Embedding; Leica: Germany), micro-sectioning were performed with a microtome (RM2245; Leica: Germany). The sections were treated with xylene and graded ethanols (Thermo Scientific; USA), and then stained with H\&E and Masson's trichrome. The stained sections were visualized with a light microscopy (CK40-F200, Olympus: Japan) and the images were stored by an image processor (UTHSCSA Image Tool 3.0, Samwoo Science Co.; Seoul, Korea).

\section{Statistical analysis}

Data were expressed as mean \pm standard deviations. Statistical significance was assessed with one-way and multi-way ANOVA by employing the SPSS 12.0 program (ver. 18.0, SPSS Inc.; IL, USA). The comparisons between two groups were carried out using a $t$-test. The samples were considered as significantly different when $p<0.05$.

\section{Results and Discussion}

\section{Chemical analyses of CMC-acrylate}

CMC-acrylate hydrogel synthesized by sequential grafting of $\mathrm{ADH}$ and acrylic acid to $\mathrm{CMC}$ via EDC/HOBT chemistry was chemically analyzed with ATR-AFIR and ${ }^{1} \mathrm{H}-\mathrm{NMR}$ spectra. The obtained polymer demonstrated successful grafting of $\mathrm{ADH}$ and acrylic acid to $\mathrm{CMC}$ as judged by both ATR-FTIR and ${ }^{1} \mathrm{H}-\mathrm{NMR}$ spectra. In an ATR-FTIR spectrum (Figure 2), native CMC spectrum showed its characteristic stretching peaks of $\mathrm{O}-\mathrm{H}$ at $3262 \mathrm{~cm}^{-1}, \mathrm{C}-\mathrm{H}$ at $2907 \mathrm{~cm}^{-1}, \mathrm{C}=\mathrm{O}$ at $1590 \mathrm{~cm}^{-1}$ and $\mathrm{C}-\mathrm{O}-\mathrm{C}$ at $1323 \mathrm{~cm}^{-1}$, and deformation peak of $\mathrm{C}-\mathrm{O}-\mathrm{H}$ at $1418 \mathrm{~cm}^{-1}$. The $\mathrm{CMC}$-acrylate showed new peaks of amide II $(-\mathrm{NHC}=\mathrm{O})$ from $\mathrm{ADH}$ at $1514 \mathrm{~cm}^{-1}$, and stretching of $\mathrm{C}-\mathrm{N}$ and $\mathrm{C}=\mathrm{C}$ from acrylic acid at $1262 \mathrm{~cm}^{-1}$ and $1710 \mathrm{~cm}^{-1}$. In an ${ }^{1} \mathrm{H}-\mathrm{NMR}$ (Figure 3) spectrum, CMCacrylate showed new peaks at 2.34, 1.59 ppm from $\mathrm{ADH}$ and 6.29, 5.87 ppm from acrylic acid $\left(\mathrm{H}_{2} \mathrm{C}=\mathrm{CH}-\right)$.

\section{Fabrication of CMC-PEO gel and porous gel film}

5\% CMC-PEO gel was spontaneously fabricated at room temperature by the mechanism of Michael type addition reaction within $5 \mathrm{~min}$ by mixing the precursor solutions of synthesized CMC-acrylate and PEO-thiols. The gelation time was estimated by measuring the time points where no flow was detected during tilting of the conical tube vial with sample solutions. The morphology of the 5\% CMC-PEO gel was evaluated with SEM after dehydration of the water-swollen gel (Figure 4-A, B). While the hydrogel surface showed smoothness with hexagonal morphologies with $82 \mu \mathrm{m}$ (Figure 4-A), its cross-sections had pores with $36 \mu \mathrm{m}$ diameter in average (Figure 4-B).

To expand its possible applications to tissue engineering, a porous CMC-PEO gel film was fabricated. Both two types of porogen particles and the CMC-PEO mixture solution were employed to create pores in the gel films (Figure 4-C, D, E and F). The porogen particles were in advance inserted in either $12 \%$ or $18 \%$ CMCPEO mixture solution for creation of different pore sizes, where the gel film fabricated by gas-forming of both 150-180 and 250-350 $\mu \mathrm{m}$ ammonium bicarbonate particles showed different pore sizes depending on particle sizes. In specific, we observed formation of pores in hydrogel in buffer medium (Figure 4-C, D, E and F) as indicated by dark circles, even though the morphologies

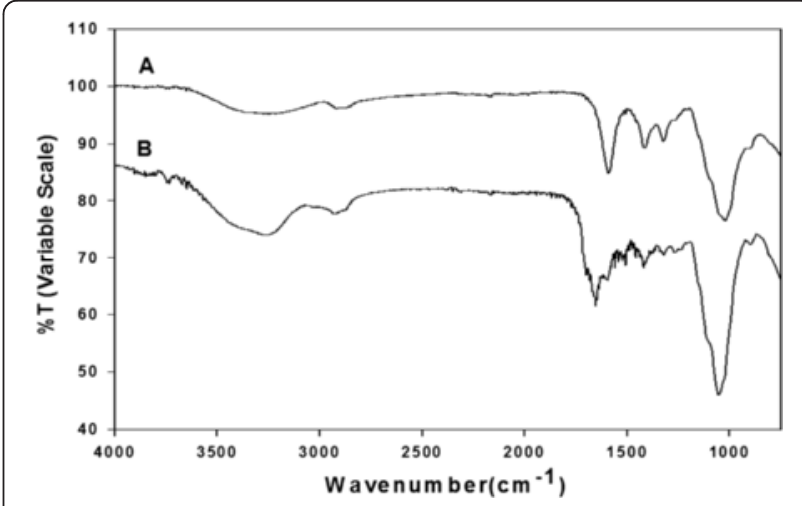

Figure 2 Chemical analyses of CMC (A) and CMC-acrylate (B) by ATR-FTIR. 


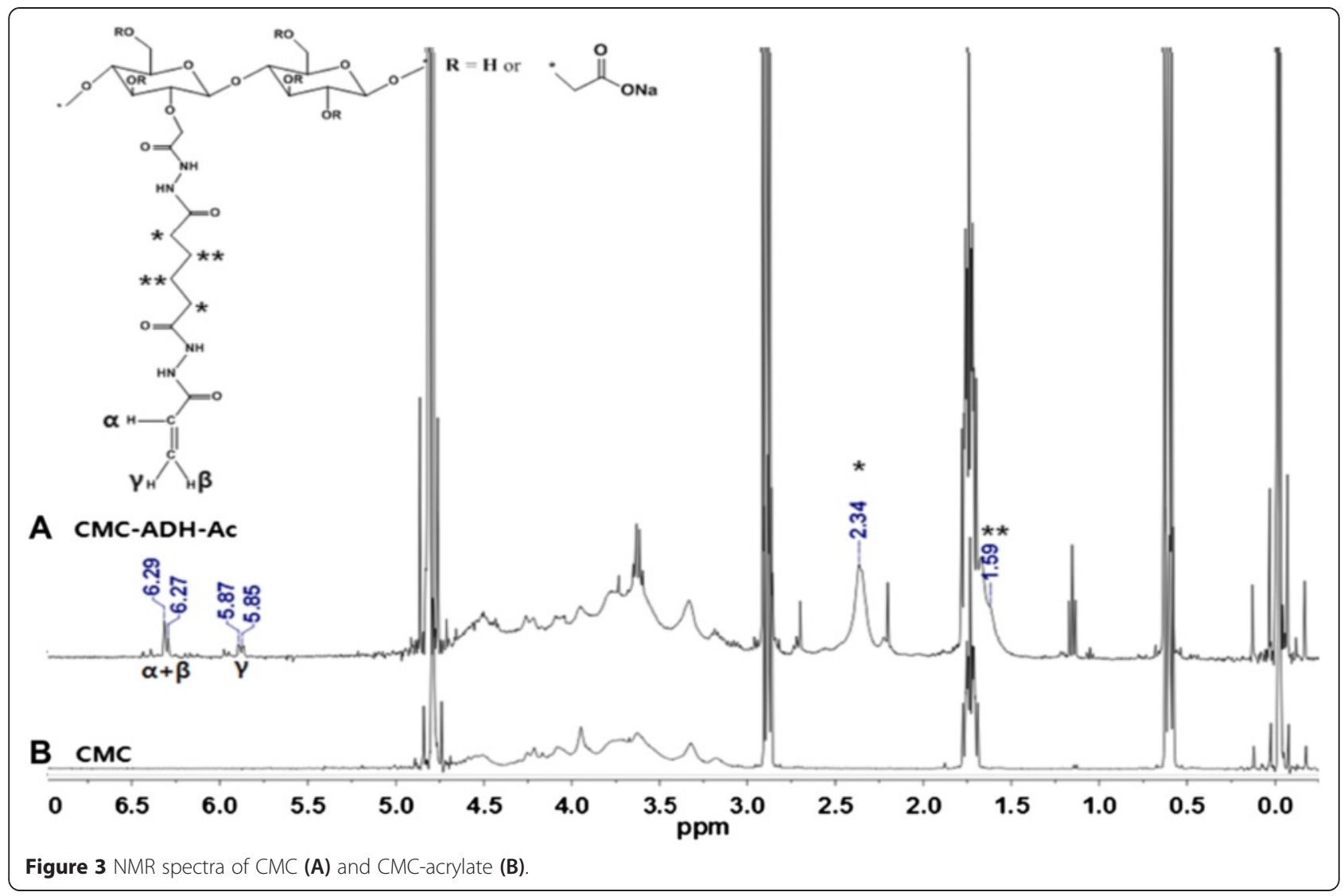

of pores could not be measured in exact sizes due to observation of different locations of the pores in gel films by light microscopy. The gel films fabricated by the porogens with larger porogen sizes $(250-350 \mu \mathrm{m}$; Figure 4-D) and higher concentration (18\%; Figure 4-D and F) showed more (Figure 4-D) and larger (Figure 4-F) pore sizes than those with smaller sizes $(150-180 \mu \mathrm{m}$; Figure 4-C) of porogens and lower concentrations (12\%; Figure 4-E) of CMC-PEO solutions. The gel films fabricated with $18 \%$ mixture solution and $250-350 \mu \mathrm{m}$ porogen particles showed approximately $33-47 \mu \mathrm{m}$ diameters of pores.

\section{Swelling of CMC-PEO gel}

Swelling of $200 \mu \mathrm{L} 5 \%$ CMC-PEO gel was evaluated by measuring its weight in water at different $\mathrm{pHs}$ after blotting off non-adherent water with Kimwipe. The hydrogels swelled differently depending on the $\mathrm{pHs}$, i.e. higher swelling in basic medium and shrinking in acidic one. In specific, while the hydrogel in $\mathrm{pH} 4$ water swelled to $138 \%$ in one hr, the hydrogel in neutral and basic water at $\mathrm{pH} 10$ swelled to 330 and 664\%, respectively (Figure 5). The CMC-PEO gels in acidic medium reached to equilibrium within $1 \mathrm{hr}$, but that in basic one did $4 \mathrm{hr}$. The sample in neutral medium showed modest swelling and reached to equilibrium slower than that in basic condition.
In vitro degradation by esterase

In vitro degradation of the 5\% CMC-PEO gel (1:1) was measured by comparing to its weight changes, when 2 , 10 , and 30 unit esterase solutions were added into $200 \mu \mathrm{L}$ gel for $108 \mathrm{hr}$ (Figure 6). The hydrogel treated with 2 unit esterase solution lost small amount of its weight, in specific, there were approximately $18 \%, 30 \%$, and $39 \%$ weight loss at the time points of 6,24 and $84 \mathrm{hr}$, respectively. When 10 and 30 unit esterase solution was added for up to $84 \mathrm{hr}$, hydrogels lost $58 \%$ and $66 \%$ in their weights.

\section{In vitro cellular behaviors inside and on the surface of CMC-PEO gel film}

Cellular behaviors of smooth muscle cells were evaluated both inside and on the surface of 5\% CMC-PEO gel films (1:1) for $7 \mathrm{~d}$ by seeding at a density of 100,000 and 10,000 cells per gel in a 24 well plate. Both cell morphologies and cell adhesion and proliferation were measured with light microscopy and CCK- 8 at day 1, 3 and 7. While the cells adhered and aggregated on its surface, the cells encapsulated in the hydrogel showed neither aggregation nor spreading, showing in a round shape. Cells were alive in green colors both on the surface of and inside the hydrogel (Figure 7-A and B). When we measured degrees of their cell adhesion and proliferation 


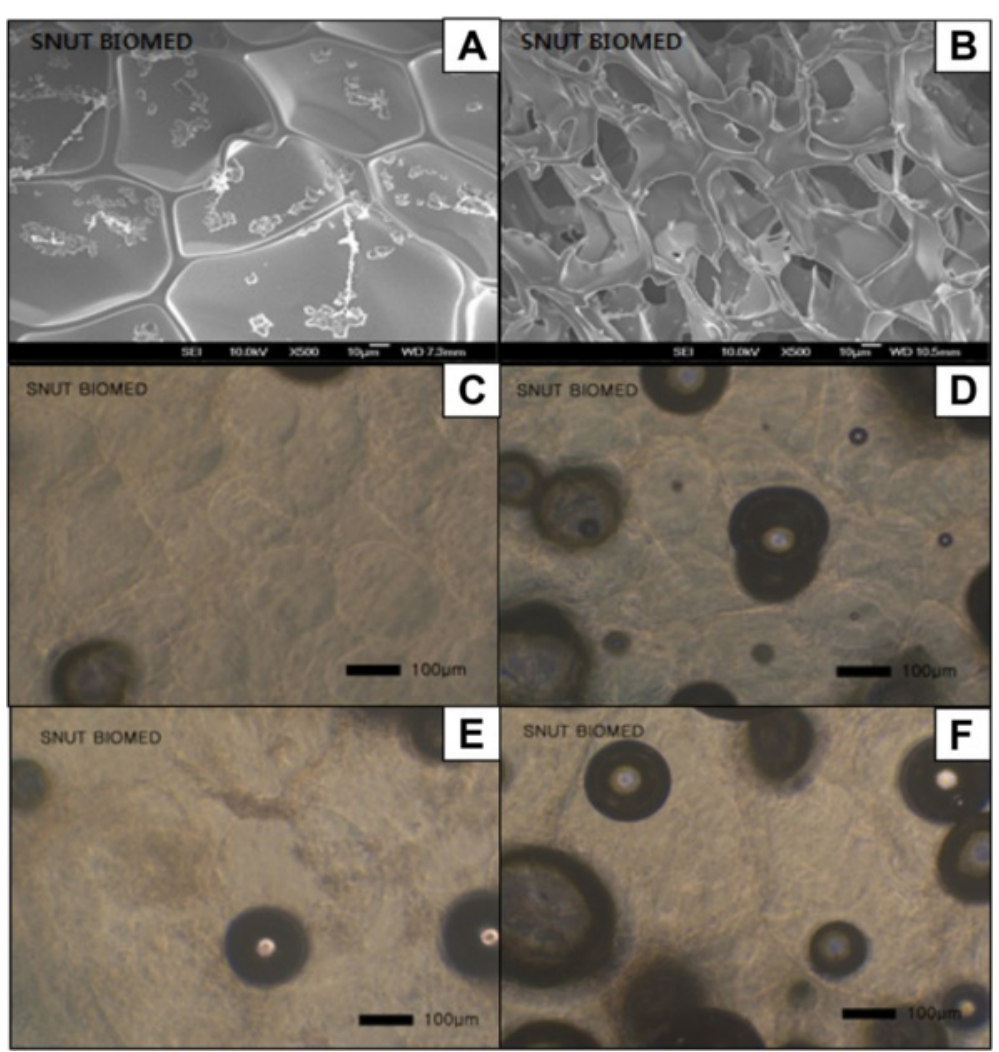

Figure 4 Morphologies of the surface (A, C, E) and x-section (B, D, F) of 5\% CMC-PEO hydrogel in dry state (A, B) and porous gel films (C to F), which were fabricated by gas foaming of ammonium bicarbonate with the sizes of 150-180 (C, D) and 250-350 (E, F) $\mu \mathrm{m}$ by employing the 12\% (C, E) and 18\% (D, F) polymer solutions, respectively.

with CCK-8, the value of their optical density decreased from 0.24 at day 1 to 0.16 and 0.15 at days 3 and 7 , respectively, indicating possibly cell detachment from the samples during medium changes (Figure 8). However, no cell death was observed.

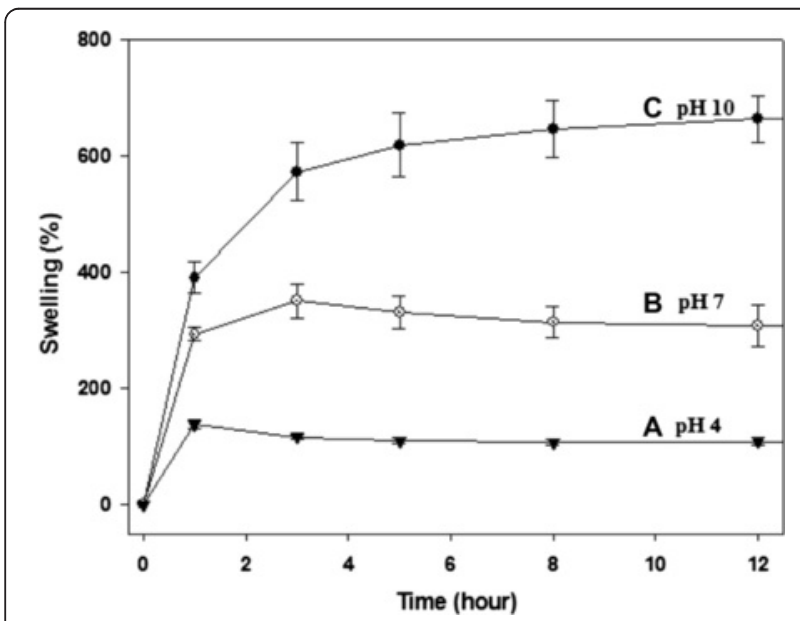

Figure 5 Swelling behaviors of CMC-PEO hydrogels in water with different $\mathrm{pHs}$.

\section{Direct contact of CMC-PEO gel on cells on the tissue} culture flask

Cellular behaviors and morphological changes were evaluated with both light and fluorescence microscopy after direct contacting of hydrogel with the cells cultured on the surface of polystyrene tissue culture flask for $24 \mathrm{hr}$. Teflon and Latex were employed as positive and negative

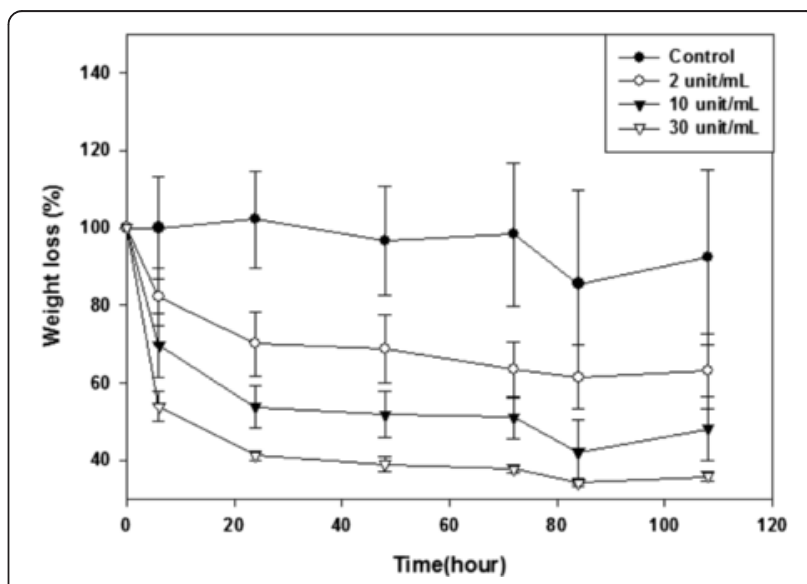

Figure 6 In vitro degradation of CMC-PEO hydrogels by esterase. 


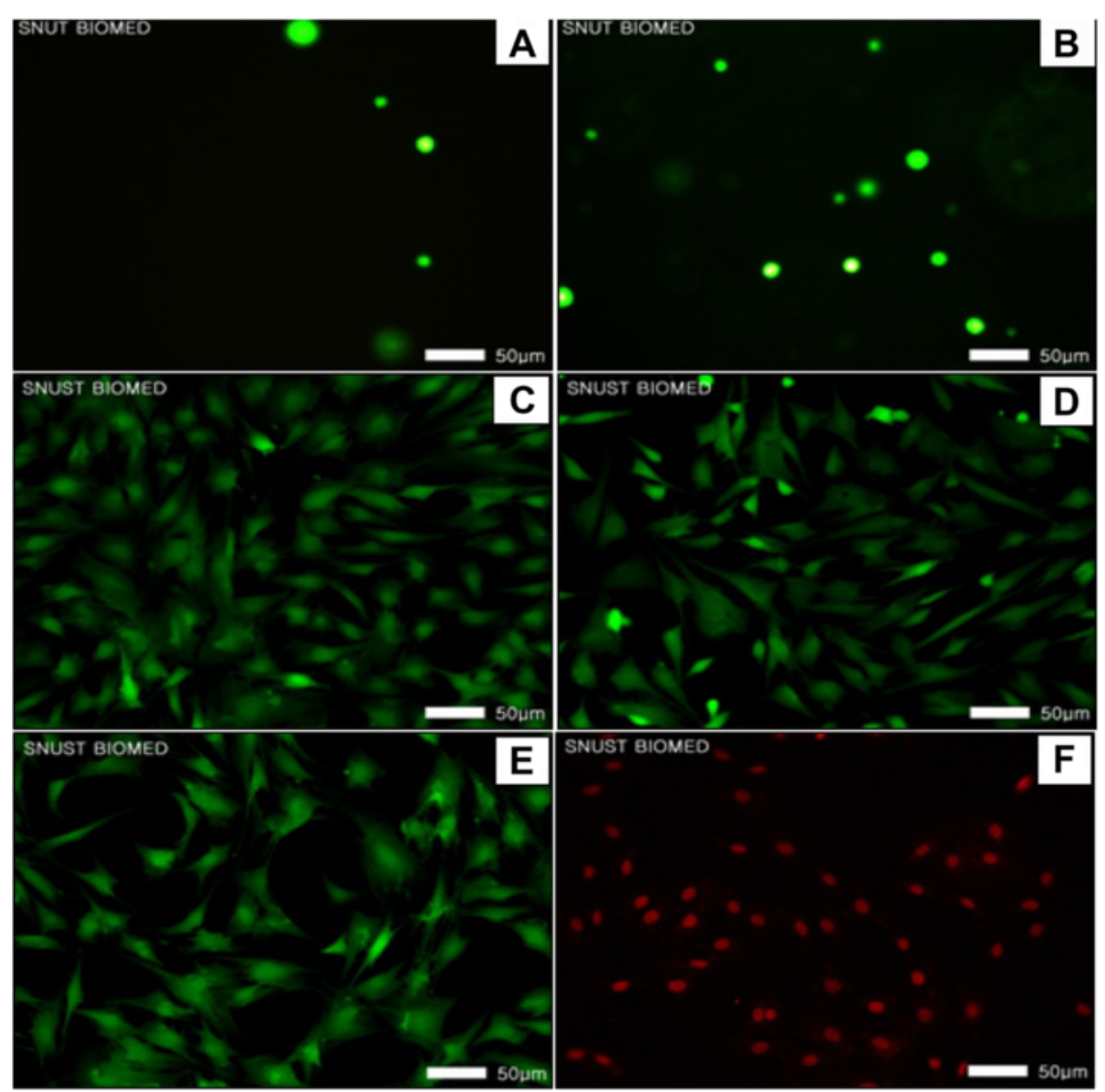

Figure 7 Morphologies of the smooth muscle cells on the surface of (A) and inside (B) CMC-PEO hydrogels, and on the control 12 well plate (C) and the cells on the well plate covered with either CMC-PEO hydrogels (D), Teflon (E) or Latex (F) for $24 \mathrm{hr}$.

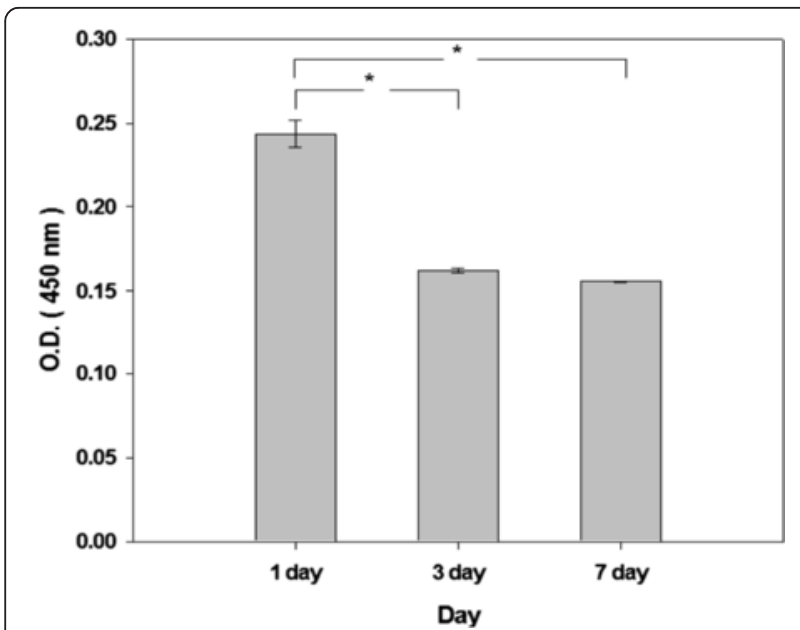

Figure 8 Proliferation behaviors of smooth muscle cells seeded at density of 10,000 cells on the surface of $5 \%$ CMC-PEO hydrogel measured by CCK-8 assay. controls, respectively. All the cells covered with Teflon (Figure 7-E) and hydrogel (Figure 7-D) were observed as live without any damages similar to those of culture flask and Teflon as shown in green color (Figure 7-C and E), but all the cells covered with negative control Latex film were observed as dead in red color (Figure 7-F). All the cells covered with hydrogel were also observed as adhered and spread on the surface of the culture flak.

\section{In vitro cytotoxicity of CMC-PEO gel by the assays of MTT/} BrdU/Neutral red

Effects of extracts of the CMC-PEO gel on compatibility of the smooth muscle cells on the culture flask were evaluated for $24 \mathrm{hr}$ at cell organ levels by the assays of MTT, BrdU and Neutral Red, which indicate its effects on mitochondria, DNA synthesis and lysosome, respectively (Figure 9). Teflon and Latex were employed as positive and negative controls, respectively, and the OD value of Teflon extract was considered as $100 \%$. While cell viabilities of the extracts of Latex were measured as 30,48 and $12 \%$ by the assays of MTT, BrdU and Neutral Red, respectively, those of the CMC-PEO gels were 


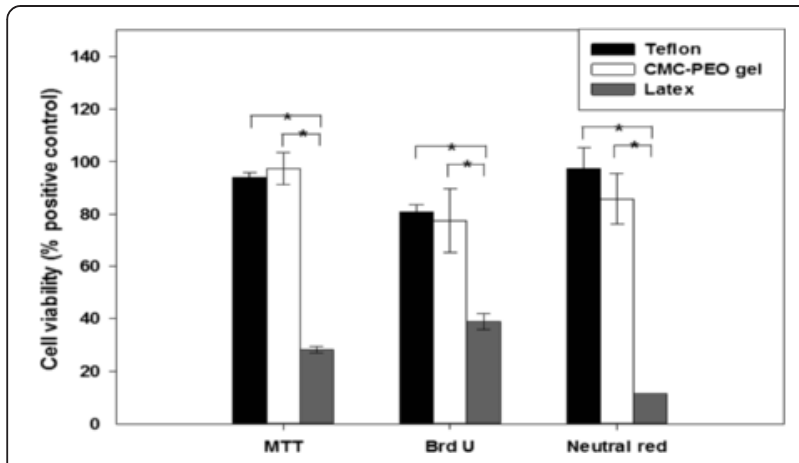

Figure 9 Cytotoxicity of the smooth muscle cells exposed to the extracts of the CMC-PEO gels for $24 \mathrm{hr}$.

measured as 103\%, $96 \%$ and $88 \%$ with no significant difference in statistics against the positive control Teflon $(\mathrm{P}=0.59,0.86,0.27)$, but with significant difference against that of negative control Latex $(\mathrm{P}=0,0.002,0)$. From these results, we concluded that the CMC-PEO hydrogel was cell-compatible.

In vitro tissue regeneration in the porous CMC-PEO gel films After seeding fibroblasts on the surface of the $5 \%$ porous CMC-PEO gel films at density of 200,000 cells $/ \mathrm{cm}^{2}$, in vitro cell culture on the surface of porous gel films for
$35 \mathrm{~d}$ showed that all the cells were live and cells had ingrown into the pores of the gel films, depending on the pore sizes as observed by fluorescence microscope (Figure 10-A, B, C and D). The porous gel films fabricated by lower polymer concentrations and larger particle sizes induced more cell ingrowth into the pores of the gel films and all the cells were observed to be live. In specific, while the porous gel films fabricated with both $18 \%$ polymer solution and $150-180 \mu \mathrm{m}$ porogens induced very small amount of cell ingrowth into its pores (Figure 10-B), those with $12 \%$ porogens showed little bit higher amount of cell ingrowth into the pores (Figure 10-A). Higher amount of cell ingrowth was observed on the porous gel films with larger pore sizes. The porous gel films fabricated with $250-350 \mu \mathrm{m}$ porogens and the polymer solutions of both 12 and $18 \%$ showed high amount of cell ingrowth (Figure 10-C, D).

Next, both cellular ingrowth and tissue regeneration of these porous gel films were evaluated by staining with $\mathrm{H} \& \mathrm{E}$ (Figure 10-E, F, G and H). While the porous gel films with smaller pore sizes fabricated by $150-180 \mu \mathrm{m}$ ammonium bicarbonate particles showed gels only in purple regardless the concentrations of its polymer solutions (Figure $10-\mathrm{E}$ and F), those by $250-350 \mu \mathrm{m}$ porogens and either 12 or $18 \%$ precursor solutions showed clear tissue formation in orange color. The porous gel

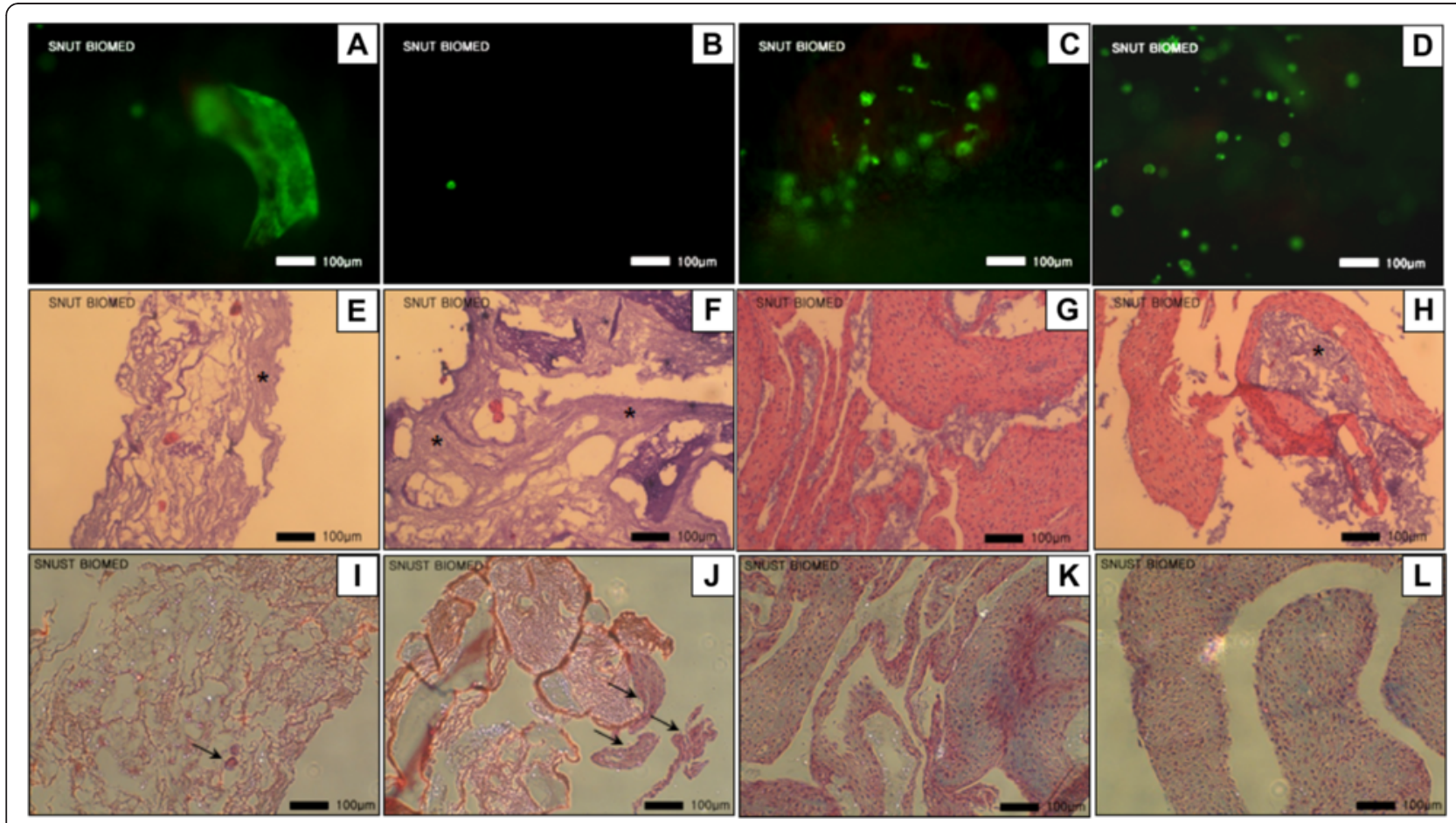

Figure 10 Ingrowth and viability of fibroblasts in the pores of the porous CMC-PEO gel films fabricated by gas-forming of 150-180 $\mu \mathrm{m}$ ammonium bicarbonate particles at the concentrations of either $12 \%(\mathbf{A}, \mathbf{E}, \mathbf{I})$ or $18 \%(\mathbf{B}, \mathbf{F}, \mathbf{J})$; 250-350 $\mu$ m ones with either $12 \%$ (C, G, K) or $18 \%(\mathbf{D}, \mathbf{H}, \mathbf{L})$ and their staining with $\mathrm{H} \& \mathrm{E}(\mathrm{E}, \mathrm{F}, \mathrm{G}$ and $\mathrm{H})$ and $\mathrm{MT}(\mathbf{I}, \mathbf{J}, \mathbf{K}$ and $\mathbf{L})$. In vitro cultures of the samples lasted for $35 \mathrm{~d}$ and observed by fluorescence (A-D) and light (E-L) microscopy. 
films fabricated with lower concentration of precursor solution (12\%; Figure 10-G) induced higher cell ingrowth and more tissue formation than those fabricated with higher concentrations (18\%; Figure 10-H) did. Tissue regeneration was further evaluated by MT staining (Figure 10-I, J, K and L). The porous gel films fabricated with $250-350 \mu \mathrm{m}$ porogens and the polymer solutions of both 12 and $18 \%$ showed formation of collagens in blue color.

\section{Conclusions}

CMC-PEO hydrogel was fabricated by mixing two precursor solutions of CMC-acrylate and PEO-hexa-thiols. Porous CMC-PEO gel films were also successfully fabricated by using porogens of ammonium bicarbonate particles with $150-180 \mu \mathrm{m}$ and $250-350 \mu \mathrm{m}$ in sizes, which were in advance mixed in precursor solutions of CMCacrylate and PEO-hexa-thiols. SEM pictures showed that while the surfaces of the porous CMC-PEO gel films had $82 \mu \mathrm{m}$, their cross-sections had $36 \mu \mathrm{m}$, in pore diameters. When the CMC-PEO gels were immersed in buffer medium at $\mathrm{pH} \mathrm{4,7}$ and 10, they swelled to $664 \%$ in basic medium at equilibrium. When in vitro biodegradation of the CMC-PEO gels was controlled by addition of different amount of esterase solutions $(2,10,30 \mathrm{unit} / \mathrm{mL})$ into the sample solutions, their degradations depended on enzyme doses employed.

In vitro biocompatibility was also evaluated for upto $7 \mathrm{~d}$ by using porcine arterial smooth muscle cells, where cells were adhered but they seemed to be detached over time as observed by CCK- 8 . Their cell compatibility tests were also verified to be excellent when tested with the assays of MTT, BrdU and Neutral red. The results showed excellent cell compatibility similar to those of Teflon, a positive control, and significantly higher than those of negative control Latex. Furthermore in vitro tests showed excellent cell viability when the cells on the surface of polystyrene culture flask were covered with CMC-PEO gel films for $24 \mathrm{hr}$.

Introduction of pores in the CMC-PEO gel films remarkably induced adhesion and migration of smooth muscle cell over $35 \mathrm{~d}$. They regenerated new extracellular matrix along the pore channels as observed by both H\&E and MT stains. All the cells in the pores were observed to be viable.

\section{Availability of supporting data}

The data sets supporting the results of this article are included within the article.

\footnotetext{
Abbreviations

CMC: carboxymethyl cellulose sodium salt; $\mathrm{ADH}$ : adipic dihydrazide; PEO: poly(ethylene oxide); CCK-8: cell counting kit-8; SEM: scanning electron microscopy; EDC: N-(3-diethylpropyl)-N-ethylcarbodiimide hydrochloride; HOBt: 1-hydroxybenzotriazole hydrate; FBS: fetal bovine serum;
}

BrdU: bromodeoxy uridine; MTT: 3-(4,5-dimethylthiazol-2-yl)-2,5diphenyltetrazolium bromide; ATR-FTIR: attenuated total reflectance -

Fourier transform infrared spectroscopy; NMR: nuclear magnetic resonance.

\section{Competing interests}

The authors declare that they have no competing interests.

\section{Authors' contributions}

$\mathrm{SL}$ primarily worked on the experiment and wrote the manuscript with SB help. SYJ, BCK, YJH and SK participated in the synthesis and evaluation of hydrogel and porous films. All authors read and approved the final manuscript.

\section{Acknowledgement}

This study was supported by the Research Program funded by the Seoul National University of Science and Technology (2014-0524) and a grant of the Korea Health Technology R\&D Project through the Korea Health Industry Development Institute (KHIDI), funded by the Ministry of Health \& Welfare, Republic of Korea (A100451).

Received: 9 February 2015 Accepted: 3 April 2015

Published online: 23 April 2015

\section{References}

1. Ramli NA, Wong TW. Sodium carboxymethyl cellulose scaffolds and their physicochemical effects on partial thickness wound healing. Intl J Pharm. 2011;403(1-2):73-82.

2. Dinarvand R, Khodaverdi E, Atyabi F, Erfan M. Thermoresponsive drug delivery using liquid crystal-embedded cellulose nitrate membranes. Drug Deliv. 2006;13(5):345-50.

3. Nouran El Badawi NE, Ramadan AR, Esawi AM, El-Morsi M. Novel carbon nanotube-cellulose acetate nanocomposite membranes for water filtration applications. Desalination. 2014;344:79-85.

4. Kang H, Liu R, Huang Y. Cellulose derivatives and graft copolymers as blocks for functional materials. Polym Intl. 2033;62(3):338-44.

5. Vlierberghe SV, Dubruel P, Schacht E. Biopolymer-based hydrogels as scaffolds for tissue engineering applications: a review. Biomacromolecules. 2011;12:1387-408

6. Gariepy ER, Leroux JC. In situ-forming hydrogels-review of temperaturesensitive systems. Eur J Pharm Biopharm. 2004;58:409-26.

7. Ramanan RM, Chellamuthu P, Tang L, Nguyen KT. Development of a temperature-sensitive composite hydrogel for drug delivery applications. Biotechnol Prog. 2006;22:118-25.

8. Kim AR, Park HS, Kim SS, Noh I. Biological evaluation of cellulose hydrogel with temperature-responsive particles. Biomater Res. 2013;17(4):181-6.

9. Yang MB, Vacanti JP, Ingber DE. Hollow fibers for hepatocyte encapsulation and transplantation-studies of survival and function in rats. Cell Transplant. 1994;3(5):373-85.

10. Risbud MV, Bhonde RR. Suitability of cellulose molecular dialysis membrane for bioartificial pancreas: in vitro biocompatibility studies. J Biomed Mater Res. 2001;54(3):436-44

11. Cullen B, Watt PW, Lundqvist C, Silcock D, Schmidt RJ, Bogan D, et al. The role of oxidized regenerated cellulose/collagen in chronic wound repair and its potential mechanism of action. Int J Biochem Cell Biol. 2002;34(12):1544-56.

12. Ovington LG. Overview of matrix metalloprotease modulation and growth factor protection in wound healing. Part 1. Ostomy Wound Manage. 2002;48(6):3-7.

13. Miyamoto $T$, Takahashi $S$, Ito H, Inagaki H, Noishiki Y. Tissue biocompatibility of cellulose and its derivatives. J Biomed Mater Res. 1989;23(1):125-33.

14. Entcheva E, Bien H, Yin L, Chung CY, Farrell M, Kostov Y. Functional cardiac cell constructs on cellulose-based scaffolding. Biomaterials. 2004;25:5753-62.

15. Xing Q, Zhao F, Chen S, McNamara J, DeCoster MA, Lvov YM. Porous biocompatible three-dimensional scaffolds of cellulose microfiber/gelatin composites for cell culture. Acta Biomater. 2010;6:2132-9.

16. Fukuya MN, Senoo K, Kotera M, Yoshimoto M, Sakata O. Enhanced oxygen barrier property of poly(ethylene oxide) films crystallite-oriented by adding cellulose single nanofibers. Polymer. 2014;55(25):5843-6.

17. Niyas AMI, Sankar S, Mohammed KP, Hayath BSK, Sastry TP. Evaluation of biomaterial containing regenerated cellulose and chitosan incorporated with silver nanoparticles. Int J Biol Macromol. 2015;72:680-6. 
18. Gabriel MO, Márcio LS, Paula BD, Pierre B, Gildásio dCD, Antônio CG Bacterial cellulose/chondroitin sulfate for dental materials scaffolds. J Biomater Tissue Eng. 2014;4(2):150-4.

19. Mikos AG, Sarakinos G, Leite SM, Vacanti JP, Langer R. Laminated three-dimensional biodegradable foams for use in tissue engineering. Biomaterials. 1993;14(5):323-30.

20. Sevillano G, Rodriguez-Puyol M, Martos R, Duque I, Lamas S, Diez-Marques $M L$, et al. Cellulose acetate membrane improves some aspects of red blood cell function in haemodialysis patients. Nephrol Dial Transplant. 1990;5(7):497-9.

21. Chang Q, Murtaza Z, Lakowicz JR, Rao G. A: Fluorescence lifetime-based solid sensor for water. Anal Chim Acta. 1997;350(1-2):97-104.

22. Doheny JG, Jervis EJ, Guarna MM, Humphries RK, Warren RAJ, Kilburn DG. Cellulose as an inert matrix for presenting cytokines to target cells: production and properties of a stem cell factor-cellulose-binding domain fusion protein. Biochem J. 1999;339:429-34.

23. Ko IK, Iwata H. An approach to constructing three-dimensional tissue Bioartif Org lii: Tissue Sourcing, Immunoisolation. Clin Trials. 2001;944:443-55.

24. Takata T, Wang HL, Miyauchi M. Migration of osteoblastic cells on various guided bone regeneration membranes. Clin Oral Impl Res. 2001;12(4):332-8.

25. De Bartolo L, Morelli S, Baer A, Drioli E. Evaluation of cell behavior related to physic-chemical properties of polymeric membranes to be used in bioartificial organs. Biomaterials. 2002;23(12):2485-97.

26. Kino Y, Sawa M, Kasai S, Mito M. Multiporous cellulose microcarrier for the development of a hybrid artificial liver using isolated hepatocytes. J Surg Res. 1998;79(1):71-6.

27. Martson M, Viljanto J, Hurme T, Saukko P. Biocompatibility of cellulose sponge with bone. Eur Surg Res. 1998;30(6):426-32.

28. Martson M, Viljanto J, Hurme T, Laippala P, Saukko P. Is cellulose sponge degradable or stable as implantation material? An in vivo subcutaneous study in the rat. Biomaterials. 1999:20(21):1989-95.

29. Kim MS, Choi YJ, Noh I, Tae G. Synthesis and characterization of in situ chitosan-based hydrogel via grafting of carboxyethyl acrylate. J Biomed Mater Res Part A. 2007;83(3):674-81.

30. Falcone SJ, Doerfler AM, Berg RA. Novel synthetic dermal fillers based on sodium carboxymethyl cellulose: comparison with crosslinked hyaluronic acid-based dermal fillers. Dermatol Surg. 2007:33:136-43.

31. Hwang CM, Sant S, Masaeli M, Kachouie NN, Zamanian B, Lee SH, et al. Fabrication of three-dimensional porous cell-laden hydrogel for tissue engineering. Biofabrication. 2010;2:035003 (12 pp).

32. Kim GW, Choi YJ, Kim MS, Park Y, Lee KB, Kim IS, et al. Synthesis and evaluation of hyaluronic acid-poly(ethylene oxide) hydrogel via Michael-type addition reaction. Curr Appl Phy. 2007;7(1):28-32.

\section{Submit your next manuscript to BioMed Central and take full advantage of:}

- Convenient online submission

- Thorough peer review

- No space constraints or color figure charges

- Immediate publication on acceptance

- Inclusion in PubMed, CAS, Scopus and Google Scholar

- Research which is freely available for redistribution 